\title{
BREVE AVERIGUAÇÃO HISTÓRICA E ELEMENTAR DA RECONVENÇÃO NO DIREITO PROCESSUAL DO TRABALHO ${ }^{1}$
}

\begin{abstract}
Luiz Fernando Vescovi
Mestre em Direito Internacional pela Universidad San Carlos (USC). Especialista em Geopolítica e Relações Internacionais pela Universidade Tuiuti do Paraná (UTP). MBA em Comércio Internacional pela Faculdade de Tecnologia Internacional (FATEC). Professor dos cursos de Direito e de Ciências Contábeis da Universidade do Oeste de Santa Catarina Campus Videira (UNOESC). Advogado trabalhista. luizfernandovescovi@bol.com.br
\end{abstract}

SUMÁRIO: Introdução 1. Origem da reconvenção 2. Aspectos históricos da reconvenção no processo trabalhista 3. Conceituação do instituto. Conclusão. Referências.

Resumo: O presente trabalho tem por pretensão trazer os elementos históricos primeiros que evidenciaram a fixação do instituto reconvencional no Brasil, perpassando pelas características pioneiras de direitos alienígenas que já anteviam o mesmo em seus ordenamentos jurídicos, de maneira bastante próspera, o que evidenciou, também, manifesto interesse na alocação deste na estrutura legal brasileira. Ademais, tem por pretensão, ainda, a análise da reconvenção sob um prisma capital no tocante ao conhecimento inicial de sua base conceitual doutrinária e finalidades essenciais - segundo suas acepções jurídicas -, tanto para a alçada processual civil (donde se origina) quanto para a órbita processual trabalhista, na qual se defende, há tempos, sua inserção de forma incisiva.

Palavras-chave: Reconvenção. Processo do trabalho. Histórico.

\section{INTRODUÇÃO}

Inicialmente, vale deixar registrado que a expressão a que se faz referência no título do presente ensaio - averiguação histórica - mostra-se apenas como um acompanhamento dos marcos principais que fizeram frente, na linha cronológico-histórica, acerca do instituto em apreço, e não uma análise escorreita da história da reconvenção. Tal assertiva é suscitada, de pronto, justificando ser proposital, haja vista a dificuldade existente em se fazer investigação minuciosa do referido instituto, no que tange à sua evolução, pela escassez de fontes bibliográficas especializada no assunto capaz de trazer subsídios mínimos para melhor construção (ainda que sintética) da linha desenvolvimentista da reconvenção.

1 Dedico este trabalho à minha namorada, Simone Belo de Souza, pelo constante e verdadeiro estímulo na produção de nossos artigos científicos e pela especial dedicação que depreende a mim, compreendendo, diariamente, e de maneira paciente, a minha paixão pela pesquisa científica. 
Ao que dispõe sobre as fontes acima referendadas, estas dizem respeito à produção de natureza intelectual e produtiva, salientando a carência de material escrito porquanto a origem da reconvenção se dá em direitos estrangeiros bastante remotos, como é o caso do Direito Romano, Germânico-Visigótico, Espanhol e Português, essencialmente. Neste ínterim, evidencia-se que esses ordenamentos jurídicos - espalhados ao redor do mundo - é que trouxeram à baila a natureza, as características, as finalidades e os objetos do instituto, da maneira em que hoje se conhece. Como tais fontes bibliográficas e documentais, gênese da concepção da reconvenção para a atmosfera jurídica, não foram pesquisadas a fundo, vez que não foram encontradas (por absoluta impossibilidade de acesso a elas) nas bibliotecas consultadas para este trabalho, atém-se apenas ao acompanhamento de seu progresso histórico, especialmente aos acontecimentos e registros que figuram em pesquisas brasileiras.

O apontamento desta ressalva é salutar vez que não se pode aceitar que se inicie a investigação de determinada matéria jurídica (ou qualquer outra de natureza científica) sem que se façam comentários voltados ao cunho histórico do que se pretende averiguar. É a noção que se tem de conhecer de onde se origina e suas aspirações inicias para facilitar o entendimento na melhor aplicação do postulado em estudo, nos dias atuais. Dessa forma, muito embora não se tenha feito possível a análise dos dados bibliográficos precedentes, ainda assim se devem trazer fatos que convençam a existência de um instituto, bem como sua eficácia na aplicação, desde os primórdios de sua concepção. É o que ocorreu (e ainda ocorre) com o processo desenvolvimentista da reconvenção no mundo e no Brasil.

Assim sendo, registra-se que será exposto somente o que a doutrina melhor descreve acerca da evolução fática na qual a reconvenção sofreu por conta do passar dos anos e/ou décadas de aplicação junto ao ordenamento jurídico pátrio, restringindo-se, assim, a uma explanação sumária dos entendimentos dos juristas que já o analisaram com maior afinco, sem, portanto, tentar buscar respostas de sua criação em sua fonte originária, decorrente da dificuldade anteriormente declarada.

\section{Origem da ReconvenÇão}

O procedimento da reconvenção encontra-se previsto no ordenamento jurídico pátrio recente desde o dia 11 de janeiro de 1973, data esta do início da vigência do atual Código de Processo Civil (Lei no 5.869), na Seção IV, intitulada "Da Reconvenção", do Capítulo II, referente às formas de resposta do réu, dentro do Título VIII, o qual dispõe sobre as previsões legais concernentes ao procedimento ordinário da Justiça Comum, mais especificamente em seus arts. 315 a 318.

Da utilização prática exacerbadamente válida e eficaz no cotidiano forense dos ordenamentos jurídicos aos quais impulsionaram o desenvolvimento do instituto da reconvenção, quais sejam, basicamente: Direito Alemão, Francês, Italiano, Espanhol e principalmente Português, tal procedimento foi alocado ao aparato sistêmico de leis e normas, no Brasil, com a pretensão de se "contra-atacar" a veracidade dos fatos originários que deram causa ao pedido primeiro do autor, quando do entendimento do réu em que as questões inicialmente averiguadas não expressam validade e/ou verdade jurídica consistente, mas sim às assertivas fáticas por este narradas, caracterizando-a como uma nova ação em que o outrora réu doravante figura no polo ativo da relação processual, entendido tecnicamente por "reconvinte", e o então autor agora aloca-se no polo passivo, na qualidade de "reconvindo". De forma sucinta, conforme assevera Norberto Trevisan Bueno (1982, p. 19): “a reconvenção é, pois, a 'actio’ do réu contra, diretamente, o autor, no mesmo processo movido por este". 
Por certo que o instituto da reconvenção foi previsto em diversos ordenamentos jurídicos, principalmente europeus, pelo fato de o Velho Continente se apresentar como sendo o berço do Direito moderno. Entretanto, aquele que melhor influenciou para a sua aplicação junto à sistemática legislativa brasileira foi justamente o Direito Português, em suas previsões normativas que se encontravam dispostas nas primeiras Ordenações promulgadas, mais especificamente dentro das Ordenações Afonsinas (1447), Manuelinas (1521) e Filipinas (1603), as quais inspiraram o legislador nacional a perceber a possível aceitabilidade deste nas aspirações primeiras do Direito Brasileiro. Levando-se em conta o fato de que a última Ordenação referendada prestou vigência no Brasil por todo o período do Império e parte do período da República, muito bem se pode afirmar a influência absoluta das instituições jurídicas portuguesas em território pátrio.

Os precedentes da reconvenção, no plano luso-brasileiro, portanto, estão positivados nas Ordenações Manuelinas, na rubrica "Das Auções, e Reconvenções" (descrita no Livro III, Título XXIV), e nas Filipinas, com a firma "Das Auções e Reconvenções” (descrita no Livro III, Título XXXIII); esta última acabou trazendo novos elementos que foram agregados no que já havia sido previsto na Ordenação anterior. Assim previa seu proêmio:

A natureza da aução e reconvenção he, que ambas andem igual passo, e ambas sejão determinadas em huma sentença. Porém primeiro se responderá ao libello do autor, e primeiro será contestado, que o do réo, e pelo conseguinte todos os outros termos e autos judiciaes; e tanto que for respondido ao libello do autor, e contestado, logo se responderá ao libello do réo, e a mesma maneira se terá dahi em diante. E quando se dér sentença diffinitiva, primeiro será julgada a aução do autor, e logo a reconvenção do réo, em tal maneira que a aução e reconvenção ambas sejão determinadas em hum tempo e em huma sentença.

Já no que concerne ao regramento próprio do Brasil, exsurge, em data de 25 de novembro de 1850 , o Regulamento $\mathrm{n}^{\mathrm{o}} 737$, que tinha por condão disciplinar e regularizar as demandas de cunho comercial nacional. Neste texto normativo, diversas disposições se encontravam positivadas e que diziam respeito, inclusive, ao procedimento a ser adotado em vários institutos jurídicos utilizados, tal como a reconvenção. Em seu bojo disciplinar é que a instrução reconvencional se mostra presente, pela primeira vez, no aparato normativo brasileiro, entre os arts. 103 a 110, onde se preceituava a apresentação simultânea desta com a contestação, em mesmo prazo pré-estipulado, para que, no mesmo ato de decisium, houvesse o julgamento concomitante à ação original. Registre-se, ainda, que por força do Decreto $\mathrm{n}^{0} 763$, de 19 de setembro de 1890 , a aplicação do Regulamento $\mathrm{n}^{\circ} 737$ alargou-se às causas de natureza cível, desde que constantes de algumas modificações, o que levou a reconvenção, também, a esta esfera processual.

No extinto Código Processual Civil Brasileiro, de 18 de setembro de 1939, (Decretolei $\left.n^{\circ} 1.608\right)$, a previsão referente à reconvenção existia, inclusive de forma bastante explícita e eficaz, porém, de pouca novidade acerca do que já havia sido positivado tanto no Código de Processo Civil quanto no Código Commercial do Distrito Federal, do ano de 1924. Ademais, seu procedimento se mostrava diverso ao que hoje se conhece, principalmente pelas diferenças no tocante ao prazo [05 (cinco) dias, segundo o art. 193] de oferecimento e sua apresentação (em mesma peça contestatória, consoante o art. 190). A admissão da reconvenção, segundo o CPC de 1939, era limitada a alguns tipos processuais, conforme previa o art. 192, e, ainda, mais relevante antevisão legal se alocava no art. 194, o qual rezava a autonomia da nova ação, afirmando que ela continuaria a surtir efeitos jurídicos quanto ao seu curso processual, independentemente de posterior desistência da ação principal. 
Enfim, com a promulgação e respectiva publicação da Lei no 5.869 (atual Código Processual Civil), do ano de 1973, o instituto reconvencional foi incorporado ao ordenamento jurídico pátrio, de maneira explícita e largamente utilizável no cotidiano forense dos operadores do Direito, em seus arts. 315 a 318, trazendo elementos mais clarividentes do que os anteriormente previstos, bem como especificações (ou peculiaridades) para a sua aplicabilidade, em órbita Processual Civil.

Salienta-se, então, que tal procedimento reconvencional é o objeto investigatório a ser esmiuçado nesta pesquisa, no que tange às noções primeiras e basilares trazidas pela vertente processual comum, donde se concebe a sua essência, enquanto instituto passível de utilização na prática forense brasileira.

\section{Aspectos Históricos da ReconvenÇão do Processo Trabalhista}

Depois de efetivamente incorporado o instituto em comento à fração processual civil nacional, tão logo se percebeu a sua eficácia como meio alternativo - fundado na celeridade processual - de se resolver um deslinde processual donde o polo passivo da relação jurídica expressa pretensão diversa daquela original, consoante dos ditames fáticos narrados pelo polo ativo, instaurando-se nova ação, com diferente pedido e causa de pedir, muito embora com exata conexão para com o pedido exordial. A reconvenção, então, esculpiu uma nova visão ao Direito no que toca à possibilidade de se compreender que, por vezes, ao réu também lhe é concedido entendimento de procedência sobre o que alega, e não mais apenas ao pleito do autor, como "verdade incondicional" em um processo judicial.

Não há a menor dúvida de que a possibilidade de se fazer a inversão dos polos litigantes, quando assim for viável e essencialmente relevante (juridicamente contextualizando) para o sistema de processamento e julgamento de ações, traz no bojo procedimental uma das características na qual se assenta toda a prestação da atividade do Poder Judiciário e o que mais espera os seus jurisdicionados, qual seja: a celeridade processual. Uma forma em que se resolva a lide (ou se instaure nova demanda) sem perder a originalidade do pedido inicial, a fim de satisfazer a real pretensão deste pedido contraposto à exordial, acabou sendo bem vista por sua rápida utilização, porquanto o interesse na aplicação de tal instituto se deu tanto por meio dos operadores do Direito, de forma geral, quanto pelos próprios jurisdicionados.

A vantagem na aplicabilidade da reconvenção junto ao Direito Processual Civil foi visivelmente percebida desde o momento em que o procedimento começou a surtir resultados satisfatórios para aqueles que dele faziam uso, gerando - como consequência natural - alta proliferação desta modalidade "defensiva" do réu com a contraposição do pedido primeiro com um novo pleito. Assim sendo, sempre que plausível (isto é, quando a lei permitia, considerando perfeitamente enquadrados seus pressupostos admissionais) sua utilização, em órbita processual, a reconvenção foi crescendo proporcionalmente com a confiança daqueles que a empregavam como ferramenta para angariar seus direitos, o que auxiliou a tramitar, cotidianamente, pedidos de natureza contraposta junto ao Poder Judiciário. Da eficiência e funcionalidade dessa espécie de resposta, despertou-se imediato interesse dos militantes na área trabalhista a fim de adequá-la ao seu ramo de labuta diária.

Entretanto, sabendo-se do fato de que o instituto é originário do Processo Civil, não houve facilitação, de maneira imediatista, de adequação plena da reconvenção em mesma 
proporcionalidade aos anseios dos operadores trabalhistas em fazer uso desta em sua esfera de atuação (Processo do Trabalho), tendo em vista que os objetivos primordiais - quando de sua concepção enquanto instrumento do Direito - eram voltados exclusivamente para que houvesse maior "fluidez" nas lides processuais cíveis e um certo "acalento", por conta das necessidades de existência dessa sistemática, por anos pleiteados, pelos jusprocessualistas da Justiça Comum.

Mesmo assim salientado e certamente compreendido pelos atuantes no segmento do Direito do Trabalho, ainda houve por bem apostar, de maneira incansável, por meio de teses e embasamentos diversos, no "amoldamento" da reconvenção para a órbita processual respectiva, vez que uma das aspirações maiores (elevado a status de peculiaridade) de tal ramo jurídico pairava, em absoluto, dentro desse instituto, e que, por isso, julgavam relevante tal adequação, qual seja: a celeridade processual.

Tamanho interesse plainou por sobre a utilização fática da reconvenção no Direito Processual do Trabalho que estudiosos de reconhecida carga doutrinária brasileira começaram a trazer, em seus cursos e manuais, diversos exemplos de seu cabimento, como é o caso de Sergio Pinto Martins (2005, p. 315), auxiliando, inclusive, a causar certa avidez entre os justrabalhistas. Como exemplos trazidos por ele estão: a) empregado estável ajuizando reclamatória trabalhista descrevendo sua demissão sem que houvesse inquérito para apuração de falta grave, vindo a pleitear reingresso ao emprego; b) empregado interpõe reconvenção sobre reclamatória trabalhista ajuizada pelo empregador, sob a alegação de faltas descritas no art. 482, da CLT. O empregado, portanto, por meio de sua reconvenção, pede indenização em dobro, vez que a falta grave foi dada como causada pelo próprio empregador; c) oferecimento de reconvenção por parte do empregador em ação de empregado pretendendo o pagamento de verbas rescisórias. Neste, o empregador contesta que houve efetiva justa causa no despedimento e ainda traz elementos novos (reconvenção) onde pleiteia o pagamento de saldo credor no qual o empregado ficou devendo primeiro, ou mesmo ressarcimento de danos de natureza dolosa originados pelo empregado, que deram ensejo ao despedimento por justa causa, dentre outras tantas variantes.

Cabe ainda, neste ínterim, salientar que a reconvenção expressa como requisitos básicos condições sine qua non para sua validade e existência no mundo jurídico, consoante preleção de Fredie Didier Jr. (2009, p. 496-497), os seguintes: I) haja uma causa pendente; II) a observância do prazo de resposta; III) competência; IV) peça autônoma; V) compatibilidade entre os procedimentos; VI) conexão e; VII) interesse processual. Alguns desses são facilmente perceptíveis de adequação imediata do rito processual civil ao rito processual trabalhista, mas outros requerem análise mais minuciosa a fim de efetivamente se extrair uma conclusão concisa de cabimento e utilização da reconvenção em alçada laboral, como são os casos, por exemplo, dos requisitos acerca do prazo de oferecimento de resposta, da obrigatoriedade de peça autônoma ou mesmo a própria compatibilidade entre os procedimentos observados.

Neste ponto é que se evidencia o momento nevrálgico da história do procedimento reconvencional na Justiça do Trabalho porquanto aqui os doutrinadores iniciam suas arguições acadêmicas sobre o que se entende como cabível ou não de determinado instituto como passível de emprego neste segmento especializado do Poder Judiciário. A dificuldade está, então, exatamente em se encontrar a resposta adequada e viável que manifesta solução para integrar tanto os requisitos basilares que compõem a reconvenção quanto as condições minimamente necessárias para que esta apresente validade e existência prática e providencial junto ao Direito Processual do Trabalho. 
Por certo que a discussão que paira sobre a abordagem feita nesta pesquisa, assim como já constatada em outras elaboradas por grandes juristas, todavia não fechou esta página "histórica" de cabimento da reconvenção ao Processo do Trabalho justamente pelo fato de que ainda não se tem um resultado pacificado (doutrinariamente e jurisprudencialmente) para que se pudesse pontuar tão somente fatos e bases teóricas veementemente cabíveis. Assim sendo, o movimento de investigação do instituto à esfera laboral encontra-se em fase de produção histórica até que em algum momento não mais seja preciso discuti-lo por conta de sua aceitação absoluta e inconteste.

\section{Conceituação do InStituto}

Uma vez compreendida a gênese e os elementos históricos, mesmo que em linhas gerais, acerca da reconvenção, passa-se a esmiuçar sua conceituação de maneira mais abrangente, tendo em vista que ela se prostra de modo um tanto complexo, principalmente pelo "incidente processual" da inversão de polos de uma relação jurídica antes instaurada. Tal complexidade se dá especialmente pelo fato de haver comprovada necessidade de acompanhar noções essenciais de matéria processual civil, para, num momento posterior, conseguir abarcar os reais objetivos de sua existência e natureza jurídica, como procedimento, à qual se subordina.

Para tanto, quando efetuado exame mais meticuloso sobre a conceituação do instituto, logo se percebe não haver tamanha complicação em compreender seus intentos primordiais; pelo contrário, acaba por trazer à baila uma verdadeira simplificação e economia de grande interesse dentro da órbita processual, para se alcançar, assim, a maneira mais célere e eficaz possível da prestação jurisdicional, a qual se intenta.

A despeito de sua etimologia, De Plácido e Silva (2000, p. 682) afirma ser a reconvenção originária do termo reconventio, muito utilizado no Direito Canônico e pelos glosadores. Ainda descreve que se apresenta da composição do conventio, de convenire, alocada como acepção jurídica na pretensão de citar judicialmente ou acusar em juízo. Para os romanos, o uso da reconvenção (que desde a época já era conhecida) expressava a denominação de mutua petito, na qual figuravam-se, os litigantes, de forma concomitante como autores e réus.

Nos dizeres do processualista Moacyr Amaral Santos (2004, p. 227) percebe-se a intenção mor da espécie reconvencional como sendo uma forma de "contra-ataque" do réu às aspirações do autor, de maneira legítima, e que acaba formando novo objeto de ação por conta de ser, exatamente, uma nova ação. A alteração nos polos litigantes num processo é que caracteriza, de imediato, a natureza do instituto em comento. In verbis:

O réu, sem prejuízo da defesa, e até sob certo aspecto reforçando-a, poderá tomar a
ofensiva. O autor poderá ter ou não razão, sem embargo do que poderá o réu ter, ou
supor que tem, uma legítima pretensão, contra ou em relação ao primeiro, que seja
juridicamente protegível, diversa da que constitui objeto da ação, e, assim, contra-
atacando, pedir ao juiz que dela conheça e a declare conforme com a vontade da lei.
Ao ataque do autor reage o réu com um contra-ataque; "à atitude estática, de quem se
defende, passa o réu à atitude dinâmica de quem, por sua vez, ofende o adversário".

Assim, a assertiva acima arrolada bem evidencia a atitude que o réu toma diante de uma questão de interesse jurídico porquanto o uso da reconvenção, como observado, não apresenta absoluta certeza de resposta jurisdicional positiva, vez que ao Estado é pedido que se declare a visão dos fatos nela descritos, descaracterizando in totum ou parcialmente, o pleito inicial, feito pelo autor. A reconvenção, portanto, não é um instituto de certeza plena, mas sim um aparato capaz de trazer à baila jurídica substancial alteração na marcha processual ordinária. 
Dos ensinamentos extraídos da lição de Luiz Guilherme Marinoni e Sérgio Cruz Arenhart (2006, p. 151-152), por seu turno, encontra-se acolhida na assertiva de que a reconvenção é uma maneira especial de resposta concedida ao réu, conferindo-lhe, assim, titularidade de uma ação própria que pode vir a originar-se da pretensão primeira do autor. Assim descrevem:

Em item anterior, viu-se as defesas de que o réu pode lançar mão a fim de evitar a
procedência da pretensão do autor. Ao lado, porém, dessas defesas, pode o réu oferecer
outra espécie de resposta, que de nenhuma forma se assemelha às defesas vistas.
Trata-se da reconvenção, resposta em que o réu deixa a posição passiva que tinha na
ação inicialmente proposta - como sujeito em face de quem o autor requer ao Estado
a atuação do direito -, passando a, também, ser titular de uma ação própria, deduzida
em detrimento do autor. (...). Essa ação do réu poderia, certamente, constituir objeto
de processo distinto, mas, por conta da conexão que guarda com o litígio exposto na
relação processual já instaurada, admite a lei possa ser a questão trazida para decisão
nos mesmos autos da ação principal.

O que evidentemente parece interessante da ideia primordial da reconvenção é que o processo, quando interposto o instituto, não gera prejuízo para nenhuma das partes, vez que este serve para modificar substancialmente o teor jurídico-material do deslinde por conta de elementos inovadores a serem conhecidos pelo julgador imparcial a dar sustentáculo para que a prestação jurisdicional estatal seja da forma mais justa possível, de acordo com o que for apresentado nos autos. A reconvenção, então, expressa importante ferramenta jurídica para solução de controvérsias segundo evidências fáticas trazidas ao processo no momento em que o pedido se contrapõe, quando a situação assim viabilizar.

De modo mais técnico, o jurista Osiris Rocha (1965, p. 24), primeiro doutrinador a ater-se ao estudo específico das hipóteses de cabimento da reconvenção em alçada juslaboral, assim dispõe sobre o instituto, trazendo no bojo acadêmico as premissas da defesa (de-fendere) e da ofensa (of-fendere), extraindo suas conclusões, embasado no princípio da economia processual:

O instituto reconvencional é resultado da política processual de economia e concentração. Por ele, o réu, que já terá de comparecer a Juízo para se defender ( $d e$ fendere), contra-aparando o golpe lançado pelo autor, aproveita a occasio juris para, em virtude de ser titular de direito contra o autor, também ofendê-lo (of-fendere). Com isto, evita-se que o réu seja obrigado a iniciar um outro processo, no mesmo Juízo, com todos os ônus por ele representados, para fazer valer um direito relacionado com aquele do autor.

A postura clássica exposta pelo doutrinador supracitado demonstra, de plano, um mínimo de formalismo necessário para que a reconvenção consiga atingir seu intento maior junto à processualística que lhe é incumbida. O período de "ocasião jurídica" explanada em sua arguição é o que justamente caracteriza o instituto como um contra-ataque que pode ser efetuado em mesmo evento processual, auxiliando, dessa maneira, à continuidade de uma demanda anteriormente instaurada. Neste cerne, não careceria, portanto, de se fazer uso de nova lide a ser intentada, com nova distribuição de processo, começando todo o trâmite, desde o início, o que, certamente, contribuiria com a morosidade da Justiça, totalmente dissonante ao que se pretende com o avanço da prestação jurisdicional atual.

Por fim, analisam-se os embasamentos do pesquisador em área trabalhista Francisco Antonio de Oliveira (1999, p. 407) quando tece relevantes comentários sobre a reconvenção já em convergência com a principal lei do Direito do Trabalho, a Consolidação das Leis do Trabalho. Neste, o avaliador, em nível acadêmico, enfatiza a não previsão da modalidade reconvencional 
junto à CLT, o que não lhe descarta viabilidade de utilização para com a Justiça Laboral, sugerindo pequena alteração no prazo fatal para a entrega da mesma face aos 15 (quinze) dias previstos na Lei Processual Civil (CPC):

A reconvenção é ação do réu contra o autor no mesmo processo. Seu fundamento está no princípio da economia processual. A Consolidação não a prevê, motivo pelo qual aplica-se a subsidiariedade do processo comum (art. 769 da CLT). O reconvindo teria quinze dias para oferecer contestação. Nada impede, no processo trabalhista, que a parte reconvinda o faça de imediato ou em menor prazo. Todavia, face à surpresa do reconvindo é de bom alvitre que a instrução prossiga em sessão posterior designada. "A desistência da ação, ou a existência de qualquer causa que a extinga, não obsta ao prosseguimento da reconvenção.” (art. 317, do CPC).

Da investigação conceitual elaborada, pode-se concluir que a reconvenção é um ato "incidental" de um processo donde o réu, no momento em que é chamado à Justiça, em razão de certa lide contra ele instaurada, contesta (defende) o feito e, se o caso in concretu assim permitir, contra-atacará o autor sob novas alegações fáticas, em momento coincidente a da peça contestatória, a fim de evidenciar fundamentos os quais devem, segundo ele, ser apreciados como fatos verídicos, e não aqueles originalmente expostos pelo autor. Ao reconvinte, então, cabe elucidar fatos que convençam o julgador de que estes são válidos, em face do reconvindo. Desta feita, nova ação é intentada, porém com elementos conectivos ao pedido exordial.

O aspecto impetuosamente prático da aplicação da natureza reconvencional, consoante elucidado pela base doutrinária acima descrita, por si só expressa sensível reforço e estímulo na sua utilização, em âmbito jurisdicional, tanto dentro da órbita do Processo Civil (de onde ela se origina) quanto no próprio Processo do Trabalho, inclusive, fartamente sustentado pelo Princípio da Subsidiariedade, positivado no art. 769, da Consolidação das Leis do Trabalho, a seguir trasladado:

Art. 769. Nos casos omissos, o direito processual comum será fonte subsidiária do direito processual do trabalho, exceto naquilo em que for incompatível com as normas deste Título.

Ademais disso, não bastasse a figura subsidiária da CLT de aceitação "implícita" da reconvenção na Justiça Laboral, ainda assenta-se tal vertente em outros fundamentos principiológicos, dentre os quais a celeridade e a economia processuais que, acaso não fossem acatados, certamente iriam abarrotar as instâncias de julgamento (varas e tribunais) de ações apenas contrapondo o pedido inicial de um processo outrora distribuído, o que confere, de pronto, naturalidade e vantagem irrestrita na utilização desse modo procedimental em exame em ambas as esferas de jurisdição.

\section{Conclusão}

Após a averiguação dos elementos precursores acerca da reconvenção, tem-se por bem concluir que o momento histórico atinente ao instituto expressou significativas mudanças ao longo dos tempos, mas, no que diz respeito ao seu sentido atual, atingiu-se um status processual que converge com a totalidade da base principiológica assentada no ordenamento jurídico brasileiro, tal como o contraditório, a ampla defesa, a isonomia processual e das partes na relação jurídica, dentre outros.

Nesse norte, a intenção maior de avaliar a reconvenção por seu breve escorço histórico é de que este se apresenta como relevante instituto por conta da finalidade que o cerca: a inversão dos polos litigantes no momento em que fatos novos são trazidos à baila jurídica, pela ocorrência 
de expressar, ao julgador, os "reais" acontecimentos dos quais o reconvinte demonstra, e que, portanto, descaracteriza a necessidade de se extinguir a ação original e posteriormente ajuizar novo tipo processual, configurando, de plano, tanto a obediência ao princípio da celeridade processual quanto a busca de uma verdade real dos fatos, e não apenas uma verdade formal, criada como um "artifício" do Direito somente para satisfazer as partes no processo, por meio de sentença prolatada pelo ente imparcial (comumente o juiz togado).

In fine, no que toca à adequação do procedimento reconvencional na Justiça do Trabalho, muito embora já se tenha publicado material doutrinário a respeito (todavia escasso), ainda esbarra-se na divergência, inclusive em elevados embates teóricos dos principais juristas laborais brasileiros e da própria jurisprudência já exarada nos tribunais pátrios de órbita trabalhista, pois não fixou-se entendimento linear ou padronizado sobre o assunto. Cabe, portanto, identificar os elementos e fundamentos primordiais antes afirmados e positivados em textos ou estudos anteriores para justamente encontrar um liame em que a reconvenção possa vir a conseguir alcançar seus intentos, também, dentro do Direito Operário, auxiliando no deslinde de diversas reclamatórias distribuídas por toda a extensão nacional. Esta é uma das explicações por se estudar o passado e as origens da reconvenção: conhecer de sua gênese para poder melhor avaliar a probabilidade de alocação desta junto ao moderno Direito Processual do Trabalho.

\section{REFERÊNCIAS}

BUENO, Norberto Trevisan. Reconvenção: prática, processo e jurisprudência. Curitiba: Juruá, 1982.

DE PLÁCIDO E SILVA. Vocabulário jurídico. 17. ed. Rio de Janeiro: Forense, 2000.

DIDIER JR., Fredie. Curso de direito processual civil. 11. ed. Salvador: Jus Podivm, 2009.

MARINONI, Luiz Guilherme; ARENHART, Sérgio Cruz. Manual do processo de conhecimento. 5. ed. São Paulo: Revista dos Tribunais, 2006.

MARTINS, Sergio Pinto. Direito processual do trabalho. 23. ed. São Paulo: Atlas, 2005.

OLIVEIRA, Francisco Antonio de. O processo na Justiça do Trabalho. 4. ed. São Paulo: RT, 1999.

ROCHA, Osiris. Da reconvenção no direito do trabalho. São Paulo: Revista dos Tribunais, 1965.

SANTOS, Moacyr Amaral. Primeiras linhas de direito processual civil. 23. ed. São Paulo: Saraiva, 2004.

\section{BRIEF HISTORICAL ASPECTS OF THE COUNTERCLAIM INSTITUTE IN BRAZIL'S LABOR PROCEDURAL LAW}

Abstract: This work focuses on historical elements of the institute of counterclaim in Brazil, under the labor procedural law perspective.

Keywords: Counterclaim. Labor procedural law. Historical aspects.

Data de recebimento: out/2013 - Data de aprovação: mar/2014 